\title{
Dietary patterns and risk of non-alcoholic fatty liver disease
}

\author{
Ammar Salehi-sahlabadi ${ }^{1}$, Samaneh Sadat ${ }^{2}$, Sara Beigrezaei ${ }^{3,4}$, Makan Pourmasomi ${ }^{*}$, Awat Feizi 6 , \\ Reza Ghiasvand ${ }^{7 *}$, Amir Hadi ${ }^{7}$, Cain C. T. Clark ${ }^{8}$ and Maryam Miraghajani ${ }^{9}, 10$
}

\begin{abstract}
Background: Nutrition is a modifiable risk factor that plays an important role in the prevention or delaying of the onset of non-alcoholic fatty liver disease (NAFLD). Previous studies have focused on NAFLD and individual nutrients, which does not take into account combinations of food that are consumed. Therefore, we aimed to investigate the relationship between major dietary patterns and NAFLD.

Methods: This case-control study was conducted on 225 newly diagnosed NAFLD patients and 450 healthy controls. Usual dietary intake over the preceding year was assessed using a validated 168-item semi-quantitative food frequency questionnaire. Major dietary patterns were determined by exploratory factor analysis.

Results: Three dietary patterns, including "western dietary pattern", "healthy dietary pattern", and "traditional dietary pattern" were identified. Subjects in the highest tertile of healthy dietary pattern scores had a lower odds ratio for NAFLD than those in the lowest tertile. Compared with those in the lowest tertile, people in the highest tertile of "western dietary pattern" scores had greater odds for NAFLD. After adjusting for potential confounding factors, "western dietary pattern" had a positive significant effect on NAFLD occurrence. In contrast, "healthy dietary pattern" was associated with a decreased risk of NAFLD. Furthermore, Higher consumption of the "traditional dietary pattern" was significantly associated with NAFLD, albeit in the crude model only.
\end{abstract}

Conclusion: This study indicated that healthy and western dietary patterns may be associated with the risk of NAFLD. The results can be used for developing interventions in order to promote healthy eating for the prevention of NAFLD.

Keywords: Dietary patterns, Nonalcoholic fatty liver disease, NAFLD, Factor analysis, Case-control study

\section{Background}

Non-alcoholic fatty liver disease (NAFLD) is defined as the presence of fat accumulation in the liver parenchyma in patients without significant alcohol consumption [1]. NAFLD elicits a wide range of hepatic changes

\footnotetext{
*Correspondence: Makan.Pourmasoumi@gmail.com; ghiasvand@hlth.mui. ac.ir

${ }^{5}$ Gastrointestinal and Liver Diseases Research Center, Guilan University

of Medical Sciences, PO Box: 73461-81746, Rasht, Iran

${ }^{7}$ Department of Community Nutrition, School of Nutrition and Food

Science, Isfahan University of Medical Sciences, PO Box: 8174673461 ,

Isfahan, Iran

Full list of author information is available at the end of the article
}

and is considered as a chronic liver disease [2]. NAFLD is considered responsible for most cryptogenic chronic liver diseases, and because of its possible progression to non-alcoholic steatohepatitis (NASH), liver cirrhosis and hepatocellular carcinoma [3, 4], it is vitally important that its identification and treatment is focused upon.

NAFLD is an important health issue in both developed and developing countries [5]. Prevalence of NAFLD in the Mediterranean region, Europe, Japan and Singapore is $36.8 \%, 20-40 \%, 9-30 \%$ and $5 \%$ respectively $[6,7]$; whilst the prevalence of NAFLD in Iran has been found to be $2.9-7.1 \%$ in the general population [8]. 
NAFLD is strongly associated with central adiposity, type 2 diabetes mellitus (T2DM), insulin resistance, hypertension and metabolic syndrome [9]; whilst some empirical data demonstrates that NAFLD is associated with an increased risk of morbidity and mortality in cardiovascular disease $[10,11]$. Obesity is associated with the presence of NAFLD; however, increased central adiposity is asserted a more important indicator of NAFLD than total body fat [12]. Accumulating evidence have indicated that high-calorie diets, especially those rich in saturated and trans fatty acids, and cholesterol, as well as fructose-rich diets, increase central adiposity, visceral fat and the incidence of NAFLD [13]. In addition, certain dietary patterns, such as a western dietary pattern, has been associated with NAFLD, independent of gender, family income and physical activity level [14]. Moreover, it has been shown that dietary pattern is one of the most important factors in preventing and treating NAFLD [15]. One previous cross-sectional study of adults aged 24 to 70 years $(n=375)$ found an increased risk of NAFLD in those with a higher intake of soft drinks, while a higher intake of omega-3-rich foods reduced the risk [16]. In another study, a high intake of take-out foods, red meat, full-fat dairy products and soft drinks, was associated with higher risk of NAFLD [14]. On the other hand, diet can modify the intestinal microbiota which is considered as and "invisible organ" in human body and can play an important role in normal metabolism and immuno-modulation [17]. The impact of gut microbiota on NAFLD has been suggested by previous studies, it can be a viable target for NAFLD treatment [18].

Given that promising association between foods and nutrients, and risk of NAFLD which have been reported by many studies [19], investigations on dietary patterns and NAFLD are very limited and most studies have focused on the role of single nutrients or foods. Dietary pattern analysis has been used to consider total food intake and the potentially synergistic effects of foods and nutrients which conceivably better reflects the complexity of the diet. Therefore, in this study, we sought to examine the association of the major dietary patterns and the risk of NAFLD among Iranian adults.

\section{Methods}

\section{Study design and population}

This study was a retrospective, age and gender matched, case-control study, which was conducted in the Metabolic Liver Disease Research Center affiliated to Isfahan University of Medical Sciences. Overall, 225 newly diagnosed NAFLD patients and 450 controls were recruited in this study. Individuals who were diagnosed with NAFLD by an expert physician based on laboratory tests and the liver sonography (presence of steatosis) were included in the case group. Healthy individuals based on laboratory tests (alanine aminotransferase $[\mathrm{ALT}]<31$ $\mathrm{UI} / \mathrm{L}$ and $41 \mathrm{UI} / \mathrm{L}$ and aspartate aminotransferase $[\mathrm{AST}]<31 \mathrm{UI} / \mathrm{L}$ and $37 \mathrm{UI} / \mathrm{L}$ in women and men, respectively) and the liver sonography (not suffering from any stages of hepatic steatosis) were considered as control group. Case and control were matched regarding age and gender.

Individuals with special dietary or physical activity regimens (due to a particular disease or weight loss or professional exercise), history of diseases such as renal and hepatic (Wilson's disease, autoimmune liver disease, hemochromatosis, virus infection, and alcoholic fatty liver), cardiovascular disease, malignancy, thyroid disorder, and autoimmune diseases were excluded from study. Participants who did not complete more than 35 items of the food frequency questionnaire and those who reported total daily energy intakes $\leq 800$ or $\geq 4500 \mathrm{kcal} / \mathrm{d}$ were also excluded. All participants provided written informed consent prior to the study enrollment.

\section{Dietary assessment}

Dietary intake was assessed using a validated 168-item semi-quantitative food frequency questionnaire (FFQ) [20]. The FFQ included a list of typical Iranian foods with standard serving sizes. Consumption frequencies of each food item were segmented into nine categories. Participants were asked to report their average dietary intake during the previous year by choosing one of the following choices: never or less than once a month, 3-4 times per month, once a week, 2-4 times per week, 5-6 times per week, once daily, 2-3 times per day, 4-5 times per day, and 6 or more times a day. Portion sizes of each food item were converted into grams by using standard Iranian household measures [21]. Daily nutrient intakes for each participant were computed using the United States Department of Agriculture's (USDA) national nutrient databank [22]. Then the frequencies of consumed foods were transformed into daily intakes. The nutrient composition of all foods was derived by using modified nutritionist IV software [23]. To analyze dietary pattern, food items were grouped into 36 different categories. Food items were included in a certain food group based on the similarity of nutrients and their association with NAFLD. Definitions of food groups in terms of food frequency questionnaire items is presented in Table 1.

\section{Anthropometric assessment}

Weight was measured using a standard digital Seca scale (made in Germany), while participants were unshod, wore minimum clothes and recorded to the nearest $100 \mathrm{~g}$. Height was measured using a mounted tape in a standing relaxed shoulder position, unshod, to 
Table 1 Food groups used in the dietary pattern analysis

\begin{tabular}{|c|c|}
\hline Food groups & Food items \\
\hline Processed meats & Sausage, kielbasa \\
\hline Red meats & Lamb, beef, ground meat \\
\hline Organ meats & Lamb-tongue, (beef) lamb-brain, (beef) lamb tripe, meat of sheep's head, leg, lamb, liver, heart and kidney. (beef) \\
\hline Fish & Fish, canned fish \\
\hline Skinless poultry & Chicken no skin \\
\hline Poultry-skin & Chicken with skin \\
\hline Eggs & Egg \\
\hline Low fat dairy & Low fat milk, without fat milk, yogurt, dried whey, cheese \\
\hline High fat dairy & Milk high fat, cocoa milk, chocolate milk, Yogurt-plain-whole milk, cream, ice cream cheese-cream \\
\hline Yogurt drink & Dough \\
\hline Soft drink & Soft drink \\
\hline Tea & Tea \\
\hline Coffee & Coffee \\
\hline Fruits & $\begin{array}{l}\text { Cantaloupe, melon, watermelon, pear, apricot, cherry, apple, peach, nectarine, plum, fig, grape, kiwi, grapefruit, orange, per- } \\
\text { simmon, tangerine, pomegranate, date, black cherry, strawberry, banana, sweet lemon, lemon cranberry, pineapple, raisin, } \\
\text { mulberry }\end{array}$ \\
\hline Natural juices & Grapefruit juice, orange juice, apple juice, melonjuice \\
\hline Canned fruits & Canned fruits, canned pineapple \\
\hline Dried fruits & Dried fig, dried peach, dried apricot, dried mulberry \\
\hline Vegetables & $\begin{array}{l}\text { Lettuce, tomato, cucumber, fines herbs, pot-herb, Pumpkin, squash, eggplant, celery, pea, string bean, raw carrot, cookedcarrot, } \\
\text { raw onion, fried onion, cabbage, cauliflower, sweet peppers, rawspinach, cooked spinach, turnip, cooked mushrooms, maize }\end{array}$ \\
\hline Nuts & Seeds, walnuts, pistachios, hazelnuts, almonds. (pumpkin, sunflower, watermelon) \\
\hline Legumes & Lentils, beans, chickpea, broad bean, soya, bean-mung, Pea \\
\hline Whole grains & Dark breads (bavaria, sangak, tafton), cookedbarley, oat \\
\hline Refined grains & White breads (lavash, baguettes), toast, rice, Spaghetti, vermicelli, pasta, wheat flour, biscuits \\
\hline Fast foods & Fried potato, hamburger, pizza \\
\hline Mayonnaise & Mayonnaise \\
\hline Tomato sauce & Tomato sauce \\
\hline Salty snacks & Crackers, cheese puffs, chips \\
\hline Olive & Olive seed, olive oil \\
\hline Sugar-sweets-desserts & $\begin{array}{l}\text { Cake, sugar, honey, Jam, sugar, sweets, gaz (an Iranian confectionery made of sugar, nuts, andtamarisk), candy, sohan (an Iranian } \\
\text { confectionery), chocolate, caramel, halva (kind of sweetmeat), donut }\end{array}$ \\
\hline Hydrogenated fats & Solid oil, fat animal, animal oil, butter, margarine \\
\hline Vegetable oils & (Except for olive oil) vegetable oil \\
\hline Potato & Cooked potato \\
\hline Garlic & Garlic \\
\hline Condiments & Juice lime, black pepper \\
\hline Salt & Salt \\
\hline Pickles & Pickles \\
\hline Broth & Broth \\
\hline
\end{tabular}

the nearest $0.5 \mathrm{~cm}$. Body mass index (BMI) was calculated as weight $(\mathrm{kg})$ divided by height in square meters $\left(\mathrm{m}^{2}\right)$. Waist circumference (WC) and hip circumference were measured with a non-stretch tape applied horizontally in standing position over the light clothes. Waist was positioned as the narrowest circumference between the lower rib margin and the superior anterior iliac spine, and hip as the maximum level between the waist and thigh. All measurements were recorded to the nearest $0.5 \mathrm{~cm}$. Waist to hip ratio (WHR) was calculated as waist circumference $(\mathrm{cm})$ divided by hip circumference $(\mathrm{cm})$. A trained dietitian conducted all the measurements in order to reduce error. 


\section{Assessment of other variables}

All participants were asked to answer demographic and socioeconomic questions including age, educational status, job, smoking status, home status, home type, foreign travel, income, and disease history. Many factors, including income, profession, housing, and education can determine socioeconomic status (SES) [24]. SES was defined based on educational level (academic and nonacademic education), family size $(\leq 4,>4$ people), acquisition (house ownership or not), and foreign travel (yes or no). For each variable of the SES score, participants were given a score of 1 if they had $\leq 4$ family members, were academically educated, owned a house, or travelled internationally. Instead, they were given a score of 0 if they had $>4$ family members, had non-academic education, had leasehold house or had not foreign travel. Then, total SES score was calculated by summing up the assigned scores (minimum SES score of 0 to maximum score of 4 ). Individuals with the score of 4 were considered as having high SES.

Data on physical activity was obtained via a short form of validated international physical activity questionnaire (IPAQ), which was presented as metabolic equivalentminutes per week (MET-min/week) [25]. All questionnaires were completed by a trained dietitian through a personal interview in a relaxed atmosphere.

\section{Statistical analysis}

To identify the major dietary patterns, based on 36 food groups, a factor analysis was conducted. Principal component analysis was used, and the factors were rotated by an orthogonal transformation (varimax rotation). The natural interpretation of the factors in conjunction with eigenvalues $>1$ and the scree plot distinguished whether a factor had to be retained. Dietary patterns were labeled on the basis of our interpretation of the data and of the previous research. Summing intakes of food groups weighted by their factor loadings computed the factor score for each pattern and each participant received a factor score for each identified pattern. Participants were categorized based on tertiles of dietary pattern scores. To compare general characteristics across tertiles, we used one-way analysis of variance (ANOVA) and chi-square tests where appropriate. Energy-adjusted intakes of foods and nutrients across tertiles of dietary patterns were examined using analysis of covariance.

Multivariable-adjusted odds ratio using logistic regression were computed for evaluating the association of dietary patterns and NAFLD in different models. In the crude model only, the impact of dietary patterns with NAFLD was computed. In model I the association was adjustment for age (continuous), gender (categorical), education (under diploma, diploma, bachelor, higher than bachelor), and marital status (married, single, widowed or divorced). Further adjustment was made for BMI, smoking (yes or no) and physical activity (METmin/ wk) in model II, additional adjustment for SES in model III and further adjustments for energy intake (kcal/d) in model IV. In all analyses, the first tertile of dietary patterns' score was considered as a reference. To assess the overall trend of odds ratios across increasing tertiles of dietary pattern scores, we treated the tertile categories as an ordinal variable in the analyses. Multivariable logistic regression models were used to obtain adjusted OR. Covariates were the same as above. The Mantel-Haenszel extension chi-square test was used to assess the overall trend of OR across increasing tertiles of dietary pattern scores. $\mathrm{P}<0.05$ was considered significant. All analyses were performed using SPSS software (version 21; SPSS Inc, Chicago, IL, USA).

\section{Result Identified major dietary patterns}

Factor analysis revealed three major dietary patterns from 36 food groups. The first one was labeled as "western pattern" which reflected the intakes of foods such as processed meats, organ meats, high fat dairy, soft drinks, refined grains, fast foods, mayonnaise, salty snacks, sugar-sweets-desserts and hydrogenated fats. The second pattern, was labeled "healthy pattern", which displayed relatively high consumption of fish, skinless poultry, low fat dairy, fresh fruits, natural juices, canned fruits, dried fruits, vegetables, nuts, olive and garlic. The third pattern labeled "traditional pattern" and showed relatively high consumption of red meat organ meats, skinless poultry, eggs, yogurt drink, tea, legumes, tomato sauce, sugarsweets-desserts, potato, condiments, salt, pickles and broth. Altogether, these three dietary patterns explained $50 \%$ of variance in primary variable. The factor loadings for each dietary pattern are presented in Table 2.

\section{General characteristics and dietary intakes of study participants}

The socio-demographic and lifestyle characteristics of the 225 cases and 450 controls are presented in Table 3. There were no statistically significant differences between case and control groups in terms of age, gender, waistcircumference and WHR. However, other variables including weight, BMI, physical activity, SES and smoking in controls were significantly different than cases $(P$ value $<0.05)$. In addition, cases had a significantly higher recorded energy intake than the controls.

The comparison of demographic and lifestyle factors of study participants in different levels of major dietary pattern scores are summarized in Table 4. Distribution of participants in terms of gender, weight, physical activity, 
Table 2 Factor-loading matrix for major dietary patterns

\begin{tabular}{|c|c|c|c|}
\hline Food groups & Western diet & Healthy diet & Traditional diet \\
\hline Processed meats & 0.63 & & - \\
\hline Red meats & - & - & 0.44 \\
\hline Organ Meats & 0.31 & - & 0.32 \\
\hline Fish & - & 0.32 & - \\
\hline Skinless poultry & - & 0.23 & 0.21 \\
\hline Poultry-skin & - & - & - \\
\hline Eggs & - & - & 0.57 \\
\hline Low fat dairy & - & 0.35 & - \\
\hline High fat dairy & 0.56 & - & - \\
\hline Yogurt drink & - & - & 0.27 \\
\hline Soft drink & 0.64 & - & - \\
\hline Tea & - & - & 0.31 \\
\hline Coffee & - & - & - \\
\hline Fruits & - & 0.62 & - \\
\hline Natural juices & - & 0.45 & - \\
\hline Canned fruits & - & 0.34 & - \\
\hline Dried fruits & - & 0.48 & - \\
\hline Vegetables & - & 0.50 & 0.25 \\
\hline Nuts & - & 0.48 & - \\
\hline Legumes & - & - & 0.48 \\
\hline Whole grains & - & - & - \\
\hline Refined grains & 0.30 & - & - \\
\hline Fast foods & 0.65 & - & - \\
\hline Mayonnaise & 0.51 & - & - \\
\hline Tomato sauce & - & - & 0.23 \\
\hline Salty snacks & 0.47 & - & - \\
\hline Olive & - & 0.45 & - \\
\hline Sugar-sweets-desserts & 0.40 & - & 0.32 \\
\hline Hydrogenated fats & 0.55 & - & - \\
\hline Vegetable oils & - & - & - \\
\hline Potato & - & - & 0.56 \\
\hline Garlic & - & 0.31 & - \\
\hline Condiments & - & 0.26 & 0.42 \\
\hline Salt & - & - & 0.20 \\
\hline Pickles & - & 0.21 & 0.32 \\
\hline Broth & - & - & 0.36 \\
\hline
\end{tabular}

Values $\leq 0.20$ were excluded for simplicity

waist and hip circumference, WHR, BMI, SES, marital status and education were significantly different across western dietary pattern categories. Moreover, there were significant differences in WHR, age and marital status in the healthy dietary pattern categories. Furthermore, across different levels of traditional dietary pattern, there were no significantly different according to participant's main characteristics.

The comparison of macro and micro-nutrients intake in different categories of major dietary patterns is illustrated in Table 5. Participants in all three tertiles of western dietary pattern had significantly different intakes of energy, protein, carbohydrate, saturated fat, linoleic fat, oleic fat, total sugar, sucrose, lactose, copper, zinc, vitamin E, vitamin C. Furthermore, comparison of nutrient intakes in the healthy dietary pattern categories showed significant differences in terms of energy, protein, cholesterol, linoleic fat, EPA, DHA, total dietary fiber, Total sugar, glucose, fructose, lactose, galactose, $\mathrm{Cu}, \mathrm{Zn}$, vitamin $\mathrm{A}$, vitamin $\mathrm{E}$, and vitamin $C$ intakes. Moreover, participants in the different tertile of traditional dietary pattern had significantly different intakes of energy, protein, carbohydrate, cholesterol, oleic fat, total sugar, glucose, fructose, lactose, galactose, $\mathrm{Fe}, \mathrm{Zn}$, vitamin $\mathrm{E}$, vitamin $\mathrm{C}$.

\section{The relationship between major dietary patterns and NAFLD}

Crude and Multivariable-adjusted odds ratios and their 95\% confidence interval of the associations between dietary patterns and NAFLD are presented in Table 6. In all models, tertile 1 (the lowest categories of adherence to dietary patterns) was defined as the reference category. Participants in the highest tertile of adherence to the western dietary pattern had significantly 2.04 times more chance for being NAFLD than those in the lowest tertile in the crude model (OR: 2.04; 95\% CI: 1.13-3.92). After adjusting for the potential confounding factors, there was a positive significant relationship between affected with NAFLD and adherence to the western dietary pattern in the model I (OR: 2.61; 95\% CI: 1.41-4.28), model II (OR: 2.82; 95\% CI: $1.68-$ 4.80), model III (OR: 3.11; 95\% CI: 2.41-5.12) and in the model IV (OR: 3.64; 95\% CI: 2.52-5.32). Furthermore, individuals in the highest tertile of adherence to the healthy dietary pattern were $41 \%$ less likely to have NAFLD, compared with those in the bottom category in the crude model (OR: 0.59; 95\% CI: 0.38-0.90). The healthy dietary pattern was associated with a pronounced decreased risk of NAFLD, even after adjusting for potential confounding factors in model I (OR: 0.54; 95\% CI: 0.34-0.83), model II (OR: 0.42; 95\% CI: 0.23-0.78), model III (OR: 0.31; 95\% CI: 0.18-0.54), model IV (OR: 0.30; 95\% CI: 0.13-0.68). This study observed a protective role for traditional dietary pattern against on NAFLD in crude model (OR:0.50; 95\% CI:0.37-0.68); however, this association was not significant after adjusting for the potential confounding variables in model I (OR: 0.98; 95\% CI: 0.64-1.49), model II (OR: 0.75; 95\% CI: 0.45-1.26), model III (OR: 0.74; 95\% CI: 0.44-1.26), model IV (OR: 1.21; 95\% CI: 0.57-2.57). 
Table 3 General Characteristics of subjects with and without nonalcoholic fatty liver

\begin{tabular}{|c|c|c|c|}
\hline Variables & Controls $(n=450)$ & Cases $(n=225)$ & $P$ value $^{\dagger}$ \\
\hline Age (year) & $37.88 \pm 8.92$ & $38.63 \pm 8.71$ & 0.72 \\
\hline Weight (kg) & $65.59 \pm 8.88$ & $83.30 \pm 10.61$ & 0.03 \\
\hline $\mathrm{BMI}\left(\mathrm{kg}^{2} / \mathrm{m}\right)$ & $24.99 \pm 3.09$ & $30.56 \pm 4.02$ & 0.002 \\
\hline Waist-circumference (cm) & $84.95 \pm 12.05$ & $102.28 \pm 11.68$ & 0.36 \\
\hline Hip-circumference (cm) & $96.75 \pm 6.03$ & $104.95 \pm 8.70$ & $<0.001$ \\
\hline WHR & $0.87 \pm 0.06$ & $0.97 \pm 0.06$ & 0.48 \\
\hline Physical activity (MET-min/wk) & $1590.30 \pm 949.44$ & $1119.03 \pm 616.35$ & $<0.001$ \\
\hline SES & $1.42 \pm 0.78$ & $1.96 \pm 0.68$ & $<0.001$ \\
\hline Energy (kcal) & $2124 \pm 187$ & $2385 \pm 164$ & 0.004 \\
\hline \multicolumn{4}{|l|}{ Marital status } \\
\hline Married & $366(81.3 \%)$ & 199 (88.4\%) & 0.02 \\
\hline Married-p & $14(3.1 \%)$ & $8(3.6 \%)$ & \\
\hline Single & $70(15.6 \%)$ & $18(8.0 \%)$ & \\
\hline \multicolumn{4}{|l|}{ Education } \\
\hline Lower than diploma & $49(10.9 \%)$ & $33(14.7 \%)$ & $<0.001$ \\
\hline Diploma & $186(41.3 \%)$ & $91(40.4 \%)$ & \\
\hline $\mathrm{BSC}$ & $143(31.8 \%)$ & $94(41.8 \%)$ & \\
\hline Higher than BSC & $72(16 \%)$ & $7(3.1 \%)$ & \\
\hline \multicolumn{4}{|l|}{ Home status } \\
\hline Owner & $323(71.8 \%)$ & $139(61.8 \%)$ & \\
\hline Tenant & $124(28.2 \%)$ & $86(38.2 \%)$ & \\
\hline \multicolumn{4}{|l|}{ Foreign travel } \\
\hline Yes & $54(12 \%)$ & $53(23.6 \%)$ & \\
\hline No & 396 (88\%) & 172 (76.4\%) & \\
\hline \multicolumn{4}{|l|}{ Family size } \\
\hline$>4$ & 135 (29.8\%) & $172(68.8 \%)$ & \\
\hline$\leq 4$ & 312 (70.2\%) & 78 (32.2\%) & \\
\hline \multicolumn{4}{|l|}{ Gender } \\
\hline Male & $233(51.8 \%)$ & 125 (55.6\%) & \\
\hline Female & 217 (48.2\%) & 100 (44.4\%) & \\
\hline \multicolumn{4}{|l|}{ Smoking } \\
\hline No & 438 (97.3\%) & 209 (92.9\%) & 0.006 \\
\hline Yes & $12(2.7 \%)$ & $16(7.1 \%)$ & \\
\hline Energy (kcal) & $2124 \pm 187$ & $2385 \pm 164$ & 0.004 \\
\hline
\end{tabular}

All values are mean $\pm S D$

${ }^{\dagger}$ Independent t-test was used for continuous variables and Chi-squared test for categorical variables

\section{Discussion}

The current study investigated the association of three dietary patterns of "western dietary pattern", "healthy dietary pattern", and "traditional dietary pattern" in Iranian adults with NAFLD. The "western dietary pattern", which mainly consists of a high intake of fast foods, soft drinks, processed meat, high-fat dairy products, hydrogenated fats, mayonnaise, salty snacks, sugar-sweet desserts, organ meats, and refined grains was significantly associated with the risk of NAFLD. This association was independent of age, gender, BMI, smoking, physical activities, SES, and energy intake. This finding indicated the negative role of diet which is enriched by fats and sweeteners. A previous study by Ritchiev et al. [26] also supported the results of the current study. The participants in the highest tertile of the "western dietary pattern" had the highest risk of NAFLD in comparison to the lowest tertile. In Zelber-Sagi et al. [27], it was demonstrated that high consumption of soft drinks was associated with the increasing risk of NAFLD in 375 adults. Moreover, it was explicated that high consumption of soft drinks increases the risk of NAFLD due to the high caloric content and/or the excessive amount of sugar (such as fructose) in these drinks. In addition, excessive fructose consumption is 


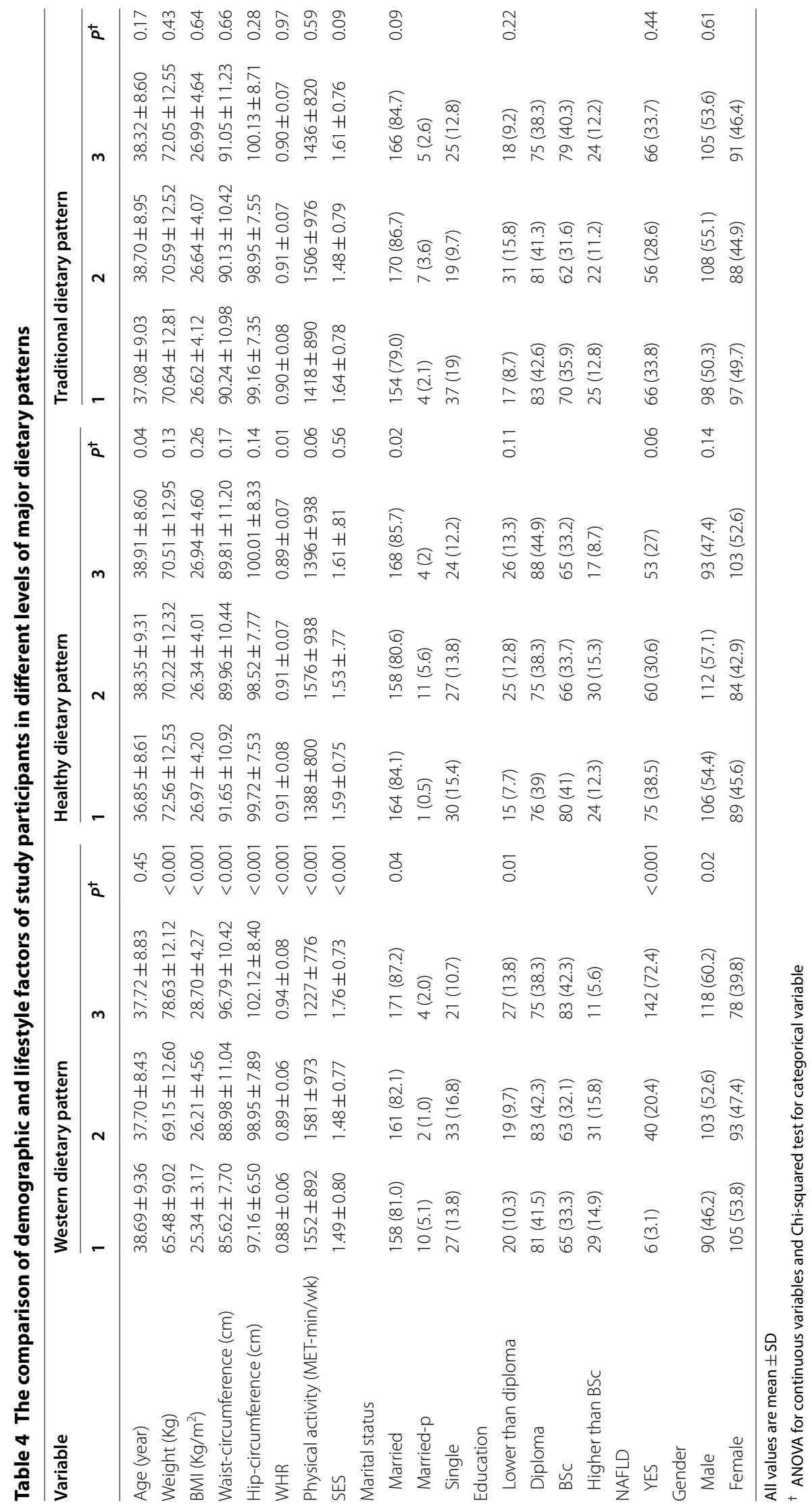




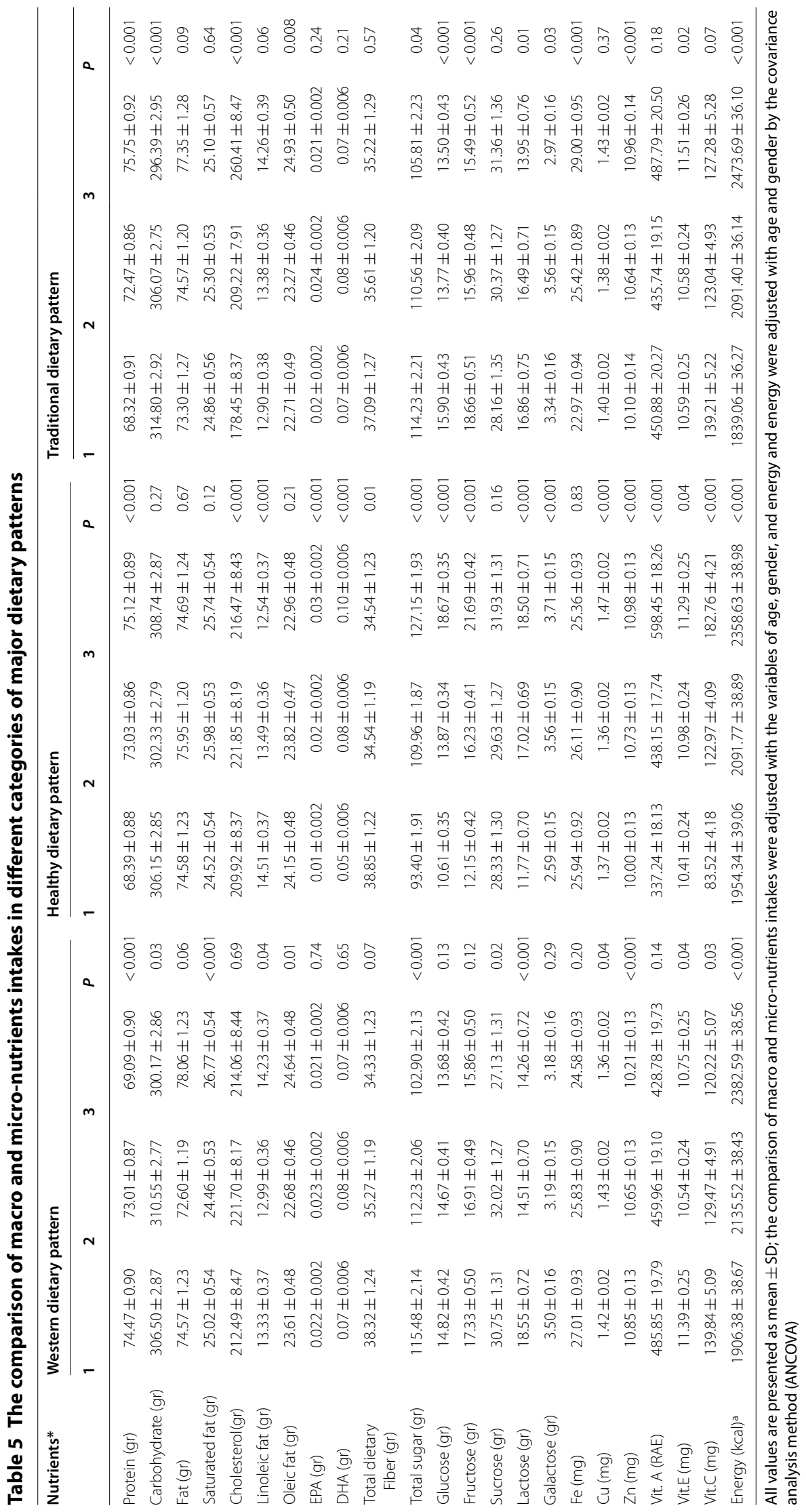




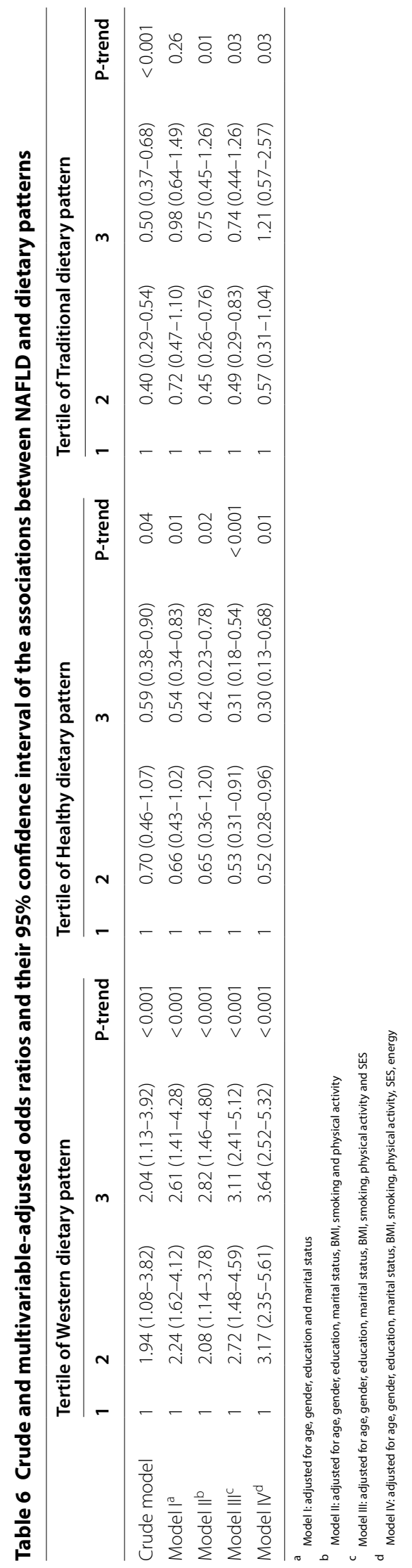


known to increase the risk of metabolic syndrome and its components, such as dyslipidemia, insulin resistance, and hypertension [14]. Moreover, refined grains, white bread, and sugar-sweets desserts, which are constituents of the "western dietary pattern", rapidly increase the insulin and glucose levels in blood, which cause insulin resistance, diabetes, and obesity [28]. Furthermore, rapid increase in blood sugar enhances the rate of "de-novo" synthesis and increases fat in liver cells [29]. It has been indicated both in animal [30] and human studies [31] that high glycemic index diet increases the fat accumulation in the liver cells and leads to hepatic steatosis. Moreover, "western dietary pattern" contains high amounts of saturated and trans fatty acids, which may affect the hepatic cells steatosis via chylomicron uptake after consuming fatty foods.

The participants in the highest tertile of "Healthy dietary pattern" had the lowest risk of affecting to NAFLD compared to the ones in the lowest tertile. "Healthy dietary pattern" is defined by high consumption of fruits, vegetables, nuts, olive oil, low-fat dairy products, fish and garlic. The current study found an inverse relation between the "healthy dietary pattern" and the risk of NAFLD, which was independent of age, gender, BMI, physical activities, SES, and energy intake. This effect could be as a consequence of high consumption of fruits and vegetables, which increases the intake of antioxidant vitamins, such as vitamins A, E, and C. Studies have shown that consuming antioxidant vitamins has a protective role against oxidative stress [32], and the risk of NAFLD [33]. Moreover, fruits and vegetables in the "Healthy dietary pattern" represent good sources of dietary fibers, which have an inverse association with insulin resistance and, thus, may conceivably reduce the risk of NAFLD [33]. Fish have high amounts of poly unsaturated fatty acids (Omega 3 ) which are capable of reducing total cholesterol and has a protective role against NAFLD [34, 35]. Similar to the "Healthy dietary pattern", a protective effect of the Mediterranean diet, which is defined as a diet rich in olive oil, fresh fruits, nuts, and vegetables; moderate in dairy products, fish, poultry and red wine; and low in red meat, eggs, sweets and processed foods [36], has been shown previously by prospective [37] and intervention studies [38, 39].

The traditional dietary pattern is different depending on the region or country, and encompasses the common foods in that country. In Esmaeillzadeh et al. [40], a traditional dietary pattern was represented by a high intake of broth, legumes, tea, whole grains and potato. In another study, traditional dietary pattern was characterized by high intake of potatoes, beans, red meat, eggs and dried fruits in men and women [41]. In the present study, "traditional dietary pattern" (due to the fact that food groups which are loaded in factor-loading analysis in third dietary pattern are similar to those of that in Iranian routine diet, we dubbed it traditional dietary pattern) consisted of high consumption of red meat organ meats, skinless poultry, eggs, yogurt drink, tea, legumes, tomato sauce, sugar-sweets-desserts, potato, condiments, salt, pickles and broth. The current study did not find any significant association between "traditional dietary pattern" and risk of NAFLD. The complex nature of this dietary pattern, which is formed by different dietary components, may have precluded significant associations. The "traditional dietary pattern" comprises healthy and unhealthy foods; and whilst healthy foods have a protective role against the emergence of NAFLD, and unhealthy foods increase the risk of NAFLD. In other words, this dietary pattern included several food items which have been reported to have negative impact on NAFLD risk factors such as red meat, organ meat, broth [42], sugar-sweets-desserts [43] and salt [44]; however, there are also food items with anti-inflammatory and anti-oxidative function. Curcumin, cinnamon, cardamom and ginger which are the most common condiments used by Iranian people have potentially liver protective effect [45-48]. In addition, tea is the habitual drink among Iranian people. It has been suggested that drinking tea could prevent incidence of NAFLD by its catching and polyphenol components [49]. In this regard, it is possible that the different effect of included food groups cause of nonsignificant result.

Our study has limitations that need to be taken into consideration. We distinguished dietary patterns by using food intake data only, while the inclusion of eating behaviors such as meal and snack patterns in the dietary pattern analysis should recommended in future studies. Restriction of the FFQ also applies to dietary pattern analyses that are based on dietary information accumulated by this method. Also, several steps in factor analysis, such as grouping of different food items, definition of a number of factors, and interpretation of those factors, were subjective. It should be noted that each pattern was also connected to other risk indicators such as BMI and socioeconomic status (SES), although we adjusted for these factors, we cannot prevent some residual confounding. In addition, due to the nature of observational studies, the causal relationships between dietary patterns and odds of NAFLD could not be made, and we could not clarify whether adherence to the diet modifies the risk of NAFLD or the disease could influence food preferences. Further studies by which the metabolic features associated to NAFLD are also considered, are necessary to confirm the vicinity of the findings. 


\section{Conclusion}

In conclusion, the present study indicated that a dietary pattern characterized by high intakes of fruits, vegetables, nuts, olive oil, low-fat dairy products, fish, and garlic was associated with reduced risk of NAFLD, while a dietary pattern with high amounts of fast foods, soft drinks, processed meat, high-fat dairy products, hydrogenated fats, mayonnaise, salty snacks, sugar-sweet desserts, organ meats, and refined grains was linked with a greater risk of NAFLD in Iranian adults. These findings should be adopted and operationalized by key stakeholders in the treatment and management of NAFLD.

\begin{abstract}
Abbreviations
NAFLD: Non-alcoholic fatty liver disease; T2DM: Type 2 diabetes mellitus; FFQ: Food frequency questionnaire; USDA: United States Department of Agriculture; BMI: Body mass index; WC: Waist circumference; WHR: Waist to hip ratio; SES: Socioeconomic status; IPAQ: International physical activity questionnaire; OR: Odd ratio; EPA: Eicosapentaenoic acid; DHA: Docosahexaenoic.
\end{abstract}

\section{Acknowledgements}

The authors would like to gratitude all the participants who kindly participated in this study.

\section{Authors' contributions}

AS, MP, and RGH the concept and design of the study; $A H, S S$, and AS data acquisition; AF statistical analysis; MM and SB interpreted the results; AS, $M P$, and CC drafted the manuscript. All authors read and approved the final manuscript.

\section{Funding}

This research received no specific grant from any funding agency in the public, commercial, or not-for-profit sectors.

\section{Availability of data and materials}

The datasets generated and analyzed during the current study are not publicly available, due to institutional policy, but may be requested directly from the corresponding author.

\section{Ethics approval and consent to participate}

This study was approved by the Research Council and the Ethics Committee of Isfahan University of Medical Sciences (Ethics code: 395408). Written informed consent was obtained from all participants.

\section{Consent for publication}

Not applicable.

\section{Competing interests}

The authors declare that they have no competing interests.

\section{Author details}

1 Student Research Committee, Department of Clinical Nutrition and Dietetics, Faculty of Nutrition and Food Technology, Shahid Beheshti University of Medical Sciences, Tehran, Iran. ${ }^{2}$ Research Committee and Department of Nutrition, School of Nutrition and Food Science, Isfahan University of Medical Sciences, Isfahan, Iran. ${ }^{3}$ Department of Nutrition, School of Public Health, Shahid Sadoughi University of Medical Sciences, Yazd, Iran. ${ }^{4}$ Nutrition and Food Security Research Center, Shahid Sadoughi University of Medical Sciences, Yazd, Iran. ${ }^{5}$ Gastrointestinal and Liver Diseases Research Center, Guilan University of Medical Sciences, PO Box: 73461-81746, Rasht, Iran. ${ }^{6}$ Department of Biostatistics and Epidemiology, School of Public Health, Isfahan University of Medical Sciences, Isfahan, Iran. ${ }^{7}$ Department of Community Nutrition, School of Nutrition and Food Science, Isfahan University of Medical Sciences, PO Box: 8174673461, Isfahan, Iran. ${ }^{8}$ Faculty Research Centre for Sport, Exercise and Life Sciences, Coventry University, Coventry, UK. ${ }^{9}$ Cancer Research Center,
Shahid Beheshti University of Medical Sciences, Tehran, Iran. ${ }^{10}$ Early Life Research Unit, Academic Division of Child Health, Obstetrics and Gynaecology, and Nottingham Digestive Disease Centre and Biomedical Research Centre, The School of Medicine, University of Nottingham, Nottingham, UK.

Received: 27 April 2020 Accepted: 14 January 2021

Published online: 28 January 2021

\section{References}

1. Teli MR, James OF, Burt AD, Bennett MK, Day CP. The natural history of nonalcoholic fatty liver: a follow-up study. Hepatology. 1995;22(6):1714-9.

2. Dixon JB, Bhathal PS, O'brien PE. Nonalcoholic fatty liver disease: predictors of nonalcoholic steatohepatitis and liver fibrosis in the severely obese. Gastroenterology. 2001;121(1):91-100.

3. Angulo P. Gl epidemiology: nonalcoholic fatty liver disease. Aliment Pharmacol Ther. 2007:25(8):883-9.

4. Farrell GC, Larter CZ. Nonalcoholic fatty liver disease: from steatosis to cirrhosis. Hepatology. 2006;43(S1):S99-112.

5. Clark JM. The epidemiology of nonalcoholic fatty liver disease in adults. J Clin Gastroenterol. 2006;40:S5-10.

6. Sharma M, Mitnala S, Vishnubhotla RK, Mukherjee R, Reddy DN, Rao PN. The riddle of nonalcoholic fatty liver disease: progression from nonalcoholic fatty liver to nonalcoholic steatohepatitis. J Clin Exp Hepatol. 2015:5(2):147-58.

7. Alisi A, Nobili V. Overlapping clinical features between NAFLD and metabolic syndrome in children. EMJ Hepatol. 2014;1:55-61.

8. Adibi A, Maleki S, Adibi P, Etminani R, Hovsepian S. Prevalence of nonalcoholic fatty liver disease and its related metabolic risk factors in Isfahan, Iran. Adv Biomed Res. 2017:6:47.

9. Machado MV, Cortez-Pinto H. Non-alcoholic fatty liver disease: what the clinician needs to know. World J Gastroenterol. 2014;20(36):12956.

10. Söderberg C, Stål P, Askling J, Glaumann H, Lindberg G, Marmur J, Hultcrantz R. Decreased survival of subjects with elevated liver function tests during a 28-year follow-up. Hepatology. 2010;51(2):595-602.

11. Adams LA, Lymp JF, Sauver JS, Sanderson SO, Lindor KD, Feldstein A, Angulo P. The natural history of nonalcoholic fatty liver disease: a population-based cohort study. Gastroenterology. 2005;129(1):113-21.

12. Pang Q, Zhang J-Y, Song S-D, Qu K, Xu X-S, Liu S-S, Liu C. Central obesity and nonalcoholic fatty liver disease risk after adjusting for body mass index. World J Gastroenterol. 2015;21(5):1650-62.

13. Fan JG, Cao HX. Role of diet and nutritional management in non-alcoholic fatty liver disease. J Gastroenterol Hepatol. 2013;28:81-7.

14. Oddy WH, Herbison CE, Jacoby P, Ambrosini GL, O'sullivan TA, Ayonrinde OT, Olynyk JK, Black LJ, Beilin LJ, Mori TA. The Western dietary pattern is prospectively associated with nonalcoholic fatty liver disease in adolescence. Am J Gastroenterol. 2013;108(5):778.

15. Montazerifar F, Karajibani M, Ansari-Moghaddam A. Evaluation of risk factors of nonalcoholic fatty liver disease in the adult population of Zahedan, Iran. Zahedan J Res Med Sci. 2014;16(8):12-5.

16. Popkin BM. The nutrition transition and its health implications in lowerincome countries. Public Health Nutr. 1998;1(1):5-21.

17. Kobyliak N, Abenavoli L, Falalyeyeva T, Mykhalchyshyn G, Boccuto L, Kononenko L, Kyriienko D, Komisarenko I, Dynnyk O. Beneficial effects of probiotic combination with omega-3 fatty acids in NAFLD: a randomized clinical study. Minerva Med. 2018;109(6):418-28.

18. Chen HT, Huang HL, Li YQ, Xu HM, Zhou YJ. Therapeutic advances in non-alcoholic fatty liver disease: a microbiota-centered view. World J Gastroenterol. 2020;26(16):1901-11.

19. Selmi C, Bowlus CL, Keen CL, Gershwin ME. Non-alcoholic fatty liver disease: the new epidemic and the need for novel nutritional approaches. J Med Food. 2007;10(4):563-5.

20. Esmaillzadeh A, Kimiagar M, Mehrabi Y, Azadbakht L, Hu FB, Willett WC. Dietary patterns, insulin resistance, and prevalence of the metabolic syndrome in women. Am J Clinical Nutr. 2007;85(3):910-8.

21. Ghafarpour M, Houshiar-Rad A, Kianfar H. The manual for household measures, cooking yields factors and edible portion of food. Tehran: Keshavarzi Press; 1999. 
22. Bowman SA, Friday JE, Moshfegh AJ. MyPyramid equivalents database, 2.0 for USDA survey foods, 2003-2004: documentation and user guide. US Department of Agriculture; 2008.

23. Hearst C, First D. Nutritionist IV: diet analysis. San Bruno, CA: First DataBank; 1995.

24. Dar NA, Shah IA, Bhat GA, Makhdoomi MA, Iqbal B, Rafiq R, Nisar I, Bhat AB, Nabi S, Masood A. Socioeconomic status and esophageal squamous cell carcinoma risk in Kashmir, India. Cancer Sci. 2013;104(9):1231-6.

25. Lee $\mathrm{PH}$, Macfarlane DJ, Lam T, Stewart SM. Validity of the international physical activity questionnaire short form (IPAQ-SF): a systematic review. Int J Behav Nutr Phys Act. 2011;8(1):115.

26. Ritchie LD, Spector P, Stevens MJ, Schmidt MM, Schreiber GB, StriegelMoore $\mathrm{RH}$, Wang M-C, Crawford PB. Dietary patterns in adolescence are related to adiposity in young adulthood in black and white females. J Nutr. 2007;137(2):399-406.

27. Zelber-Sagi S, Nitzan-Kaluski D, Goldsmith R, Webb M, Blendis L, Halpern Z, Oren R. Long term nutritional intake and the risk for non-alcoholic fatty liver disease (NAFLD): a population based study. J Hepatol. 2007;47(5):711-7.

28. Liu S, Willett WC, Stampfer MJ, Hu FB, Franz M, Sampson L, Hennekens $\mathrm{CH}$, Manson JE. A prospective study of dietary glycemic load, carbohydrate intake, and risk of coronary heart disease in US women. Am J Clin Nutr. 2000;71(6):1455-61.

29. Schwarz J-M, Linfoot P, Dare D, Aghajanian K. Hepatic de novo lipogenesis in normoinsulinemic and hyperinsulinemic subjects consuming high-fat, low-carbohydrate and low-fat, high-carbohydrate isoenergetic diets. Am J Clin Nutr. 2003;77(1):43-50.

30. Scribner KB, Pawlak DB, Ludwig DS. Hepatic steatosis and increased adiposity in mice consuming rapidly vs slowly absorbed carbohydrate. Obesity. 2007;15(9):2190-9.

31. Valtuena S, Pellegrini N, Ardigo D, Del Rio D, Numeroso F, Scazzina F, Monti L, Zavaroni I, Brighenti F. Dietary glycemic index and liver steatosis. Am J Clin Nutr. 2006;84(1):136-42.

32. Harrison SA, Torgerson S, Hayashi P, Ward J, Schenker S. Vitamin E and vitamin $C$ treatment improves fibrosis in patients with nonalcoholic steatohepatitis. Am J Gastroenterol. 2003;98(11):2485-90.

33. Musso G, Gambino R, De Michieli F, Cassader M, Rizzetto M, Durazzo M, Fagà E, Silli B, Pagano G. Dietary habits and their relations to insulin resistance and postprandial lipemia in nonalcoholic steatohepatitis. Hepatology. 2003;37(4):909-16

34. Tanaka N, Sano K, Horiuchi A, Tanaka E, Kiyosawa K, Aoyama T. Highly purified eicosapentaenoic acid treatment improves nonalcoholic steatohepatitis. J Clin Gastroenterol. 2008;42(4):413-8.

35. Kris-Etherton PM, Pearson TA, Wan Y, Hargrove RL, Moriarty K, Fishell V, Etherton TD. High-monounsaturated fatty acid diets lower both plasma cholesterol and triacylglycerol concentrations-. Am J Clin Nutr. 1999;70(6):1009-15.

36. Hołowko-Ziółek J, Cięszczyk P, Biliński J, Basak GW, Stachowska E. What model of nutrition can be recommended to people ending their professional sports career? An analysis of the Mediterranean diet and the CRON diet in the context of former athletes. Nutrients. 2020;12(12):3604.
37. Kouvari M, Boutari C, Chrysohoou C, Fragkopoulou E, Antonopoulou S, Tousoulis D, Pitsavos C, Panagiotakos DB, Mantzoros CS. Mediterranean diet is inversely associated with steatosis and fibrosis and decreases tenyear diabetes and cardiovascular risk in NAFLD subjects: Results from the ATTICA prospective cohort study. Clin Nutr. 2020. S0261-5614(20)306051. https://doi.org/10.1016/j.clnu.2020.10.058.

38. Kaliora AC, Gioxari A, Kalafati IP, Diolintzi A, Kokkinos A, Dedoussis GV. The effectiveness of Mediterranean diet in nonalcoholic fatty liver disease clinical course: an intervention study. J Med Food. 2019:22(7):729-40.

39. Abenavoli L, Greco M, Milic N, Accattato F, Foti D, Gulletta E, Luzza F. Effect of Mediterranean diet and antioxidant formulation in non-alcoholic fatty liver disease: a randomized study. Nutrients. 2017;9(8):870.

40. Esmaeillzadeh A, Azadbakht L, Khoshfetrat MR, Kimiagar M. Major dietary patterns, general and central adiposity among Tehrani female teachers. Health Syst Res. 2011;6(4):676-89.

41. Mohammadifard N, Sarrafzadegan N, Nouri F, Sajjadi F, Alikhasi H, Maghroun M, Kelishadi R, Iraji F, Rahmati M. Using factor analysis to identify dietary patterns in Iranian adults: Isfahan Healthy Heart Program. Int J Public Health. 2012;57(1):235-41.

42. Zelber-Sagi S, Ivancovsky-Wajcman D, Isakov NF, Webb M, Orenstein D, Shibolet O, Kariv R. High red and processed meat consumption is associated with non-alcoholic fatty liver disease and insulin resistance. J Hepatol. 2018;68(6):1239-46.

43. Lim JS, Mietus-Snyder M, Valente A, Schwarz J-M, Lustig RH. The role of fructose in the pathogenesis of NAFLD and the metabolic syndrome. Nat Rev Gastroenterol Hepatol. 2010;7(5):251.

44. Shen X, Jin C, Wu Y, Zhang Y, Wang X, Huang W, Li J, Wu S, Gao X. Prospective study of perceived dietary salt intake and the risk of non-alcoholic fatty liver disease. J Hum Nutr Diet. 2019;32(6):802-9.

45. Sahebkar A. Potential efficacy of ginger as a natural supplement for nonalcoholic fatty liver disease. World J Gastroenterol. 2011;17(2):271.

46. Daneshi-Maskooni M, Keshavarz SA, Qorbani M, Mansouri S, Alavian SM, Badri-Fariman M, Jazayeri-Tehrani SA, Sotoudeh G. Green cardamom increases Sirtuin-1 and reduces inflammation in overweight or obese patients with non-alcoholic fatty liver disease: a double-blind randomized placebo-controlled clinical trial. Nutr Metab. 2018;15(1):63.

47. Hajimonfarednejad M, Ostovar M, Raee MJ, Hashempur MH, Mayer JG, Heydari M. Cinnamon: a systematic review of adverse events. Clin Nutr. 2019;38(2):594-602.

48. Mansour-Ghanaei F, Pourmasoumi M, Hadi A, Joukar F. Efficacy of curcumin/turmeric on liver enzymes in patients with non-alcoholic fatty liver disease: a systematic review of randomized controlled trials. Integr Med Res. 2019;8(1):57-61.

49. Masterjohn C, Bruno RS. Therapeutic potential of green tea in nonalcoholic fatty liver disease. Nutr Rev. 2012;70(1):41-56.

\section{Publisher's Note}

Springer Nature remains neutral with regard to jurisdictional claims in published maps and institutional affiliations.

\footnotetext{
Ready to submit your research? Choose BMC and benefit from:

- fast, convenient online submission

- thorough peer review by experienced researchers in your field

- rapid publication on acceptance

- support for research data, including large and complex data types

- gold Open Access which fosters wider collaboration and increased citations

- maximum visibility for your research: over 100M website views per year
}

At BMC, research is always in progress.

Learn more biomedcentral.com/submissions 